University of Nebraska - Lincoln

DigitalCommons@University of Nebraska - Lincoln

\title{
Eating disorder pathology among overweight treatment-seeking youth: Clinical correlates and cross-sectional risk modeling
}

\author{
Kamryn T. Eddy \\ Boston University \\ Marian Tanofsky-Kraff \\ Uniformed Services University of the Health Sciences \\ Heather Thompson-Brenner \\ Boston University \\ David B. Herzog \\ Massachusetts General Hospital \\ Timothy A. Brown \\ Boston University \\ See next page for additional authors
}

Follow this and additional works at: https://digitalcommons.unl.edu/usuhs

Part of the Medicine and Health Sciences Commons

Eddy, Kamryn T.; Tanofsky-Kraff, Marian; Thompson-Brenner, Heather; Herzog, David B.; Brown, Timothy A.; and Ludwig, David S., "Eating disorder pathology among overweight treatment-seeking youth: Clinical correlates and cross-sectional risk modeling" (2007). Uniformed Services University of the Health Sciences. 25.

https://digitalcommons.unl.edu/usuhs/25

This Article is brought to you for free and open access by the U.S. Department of Defense at DigitalCommons@University of Nebraska - Lincoln. It has been accepted for inclusion in Uniformed Services University of the Health Sciences by an authorized administrator of DigitalCommons@University of Nebraska Lincoln. 


\section{Authors}

Kamryn T. Eddy, Marian Tanofsky-Kraff, Heather Thompson-Brenner, David B. Herzog, Timothy A. Brown, and David S. Ludwig 


\title{
Eating disorder pathology among overweight treatment-seeking youth: Clinical correlates and cross-sectional risk modeling
}

\author{
Kamryn T. Eddy a,b,c,*, Marian Tanofsky-Kraff ${ }^{\mathrm{d}}$, Heather Thompson-Brenner ${ }^{\mathrm{a}}$, \\ David B. Herzog ${ }^{\mathrm{e}}$, Timothy A. Brown ${ }^{\mathrm{a}}$, David S. Ludwig ${ }^{\mathrm{b}}$ \\ ${ }^{a}$ Center for Anxiety and Related Disorders, Boston University, 648 Beacon Street, 6th Floor, Boston, MA 02215, USA \\ ${ }^{\mathrm{b} C h i l d r e n ' s ~ H o s p i t a l ~ B o s t o n, ~} 300$ Longwood Avenue, Boston, MA 02115, USA \\ ${ }^{\mathrm{c}}$ Department of Psychiatry, University of Chicago Hospitals, MC 3077, 5841 S. Maryland Avenue, Chicago, IL 60637, USA \\ ${ }^{\mathrm{d}}$ Department of Medical and Clinical Psychology, Uniformed Services University of the Health Sciences, 4301 Jones Bridge Road, \\ Bethesda, MD 20814, USA \\ ${ }^{\mathrm{e}}$ Department of Psychiatry, Massachusetts General Hospital, 55 Fruit Street, Boston, MA 02114, USA
}

Received 14 December 2006; received in revised form 5 March 2007; accepted 29 March 2007

\begin{abstract}
Preliminary research suggests that pediatric overweight is associated with increased eating disorder pathology, however, little is known about which overweight youth are most vulnerable to eating disorder pathology. We therefore investigated 122 overweight treatment-seeking youth to describe eating disorder pathology and mental health correlates, and to identify psychopathological constructs that may place overweight youth at increased risk for eating disorder pathology. Youth participated in a comprehensive assessment of eating disorders, mood and anxiety disorders, general psychopathology, and risk variables involving semi-structured clinical interviews and self- and parent-report questionnaires prior to the initiation of weight-loss treatment. Ten youth met criteria for an eating disorder, and over one-third endorsed recent binge eating. Eating disorder pathology was associated with depressive and anxious symptoms $(p$ 's $<0.001)$. Structural equation modeling indicated increased negative affect, teasing experience, and thin-ideal internalization, and decreased perfectionism were associated with increased eating disorder pathology. Findings corroborate earlier work indicating that eating disorder pathology is elevated and clinically significant in overweight treatment-seeking youth, bolstering the need for mental health assessment of such individuals. Cross-sectional modeling proposed key variables that relate to eating disorder pathology in overweight treatment-seeking youth, which following prospective replication, may inform the development of effective interventions for overweight and eating disorders.
\end{abstract}

(C) 2007 Elsevier Ltd. All rights reserved.

Keywords: Pediatric overweight; Eating disorder; Binge eating; Structural equation modeling; Risk modeling

\footnotetext{
*Corresponding author. Present address: Department of Psychiatry, University of Chicago Hospitals, MC 3077, 5841 S. Maryland Avenue, Chicago, IL 60637, USA. Tel.: + 1773702 1546; fax: + 17737029929.

E-mail address: kamryn@bu.edu (K.T. Eddy).
} 


\section{Introduction}

The prevalence of pediatric overweight in the United States is of significant concern. Approximately $33 \%$ of youth are overweight (body mass index $[\mathrm{BMI}] \geqslant 95$ th percentile for age and gender) or at risk for overweight $(85$ th $\leqslant$ BMI $<95$ th percentile for age and gender) (Ogden et al., 2006). Pediatric overweight carries serious medical risks including elevated blood pressure, type II diabetes mellitus, heart disease, respiratory disease, and dyslipidemia (Botero \& Wolfsdorf, 2005; Dietz, 1995; Ebbeling, Pawlak, \& Ludwig, 2002), and is often predictive of adult obesity (Whitaker, Wright, Pepe, Siedel, \& Dietz, 1997). Further, pediatric overweight is associated with increased mortality independent of adult obesity (Must, Jacques, Dallal, Bajema, \& Dietz, 1992).

Overweight youth may be at increased risk for psychosocial difficulties, particularly, eating disorder (ED) pathology (e.g., Stice, 2002). As binge eating is commonly associated with overweight (Spitzer et al., 1992, 1993), binge eating disorder (BED) and sub-diagnostic threshold binge eating are of interest among overweight youth. BED is currently recognized in the Diagnostic and Statistical Manual of Mental Disorders (DSM-IV-TR; American Psychiatric Association [APA], 2000) as a diagnostic category in need of further study and as a type of ED not otherwise specified (EDNOS) characterized by recurrent binge eating (overeating accompanied by loss of control occurring on average at least twice weekly for 6 months) and marked distress in the absence of regular compensatory behaviors (APA, 2000). Binge episodes may be associated with a cluster of symptoms including eating rapidly, eating until uncomfortably full, eating large amounts in the absence of hunger, eating in secret due to embarrassment, and feeling disgusted, depressed, or guilty after eating (APA, 2000).

Preliminary research suggests that ED pathology is prevalent among overweight youth. To date, 10 reports (including seven separate samples) have described BED and binge eating among youth seeking weight-loss treatment, finding that approximately $20-35 \%$ endorse binge eating at sub-diagnostic threshold frequencies (Berkowitz, Stunkard, \& Stallings, 1993; Britz et al., 2000; Decaluwe \& Braet, 2003, 2004; Decaluwe, Braet, \& Fairburn, 2003; Glasofer et al., 2007; Goossens, Braet, \& Decaluwe, 2007; Isnard et al., 2003; Levine, Ringham, Kalarchian, Wisniewski, \& Marcus, 2006; Severi, Verri, \& Livieri, 1993). These estimates are only slightly lower than rates of binge eating among obese treatment-seeking adults (e.g., Spitzer et al., 1993) and are increased compared to healthy weight youth (for review, see Tanofsky-Kraff, in press).

A growing body of literature suggests the clinical significance of ED pathology among overweight youth. Cross-sectional studies indicate binge eating in overweight youth suggests a more severe psychological profile. For example, severe body dissatisfaction and shape/weight concerns are increased in overweight youth and associated with binge eating (Berkowitz et al., 1993; Decaluwe \& Braet, 2003, 2004; Decaluwe et al., 2003; Goosens et al., in press; Tanofsky-Kraff et al., 2004). Additionally, there is some support for a positive association between binge eating and depression/anxiety (e.g., Berkowitz et al., 1993; Glasofer et al., in press; Goosens et al., in press; Isnard et al., 2003; Morgan et al., 2002), although this association has not been supported in all studies (Decaluwe et al., 2003; Tanofsky-Kraff et al., 2004). Such findings have clinical relevance as increased psychopathology has been associated with poorer weight-loss treatment outcome (Epstein, Wisniewski, \& Weng, 1994).

Further, longitudinal research suggests that ED pathology may indicate a poor prognosis in overweight youth. Binge eating has been associated with excessive weight gain over time (Stice, Cameron, Killen, Hayward, \& Taylor, 1999; Stice, Presnell, \& Spangler, 2002; Tanofsky-Kraff et al., 2006), which may increase medical risks and the likelihood of adult obesity. Likewise, follow-up studies suggest ED pathology is associated with a worse outcome for treatment-seeking overweight youth (i.e., less weight loss; Braet, 2006). Finally, longitudinal community studies suggest subthreshold ED pathology is associated with the development of full-syndrome EDs (for review, see Stice, 2002). As such, ED pathology may be of clinical importance in overweight youth, suggesting that its detection has relevance both for intervention of overweight and prevention of EDs.

To date, there is little evidence indicating which overweight youth are most vulnerable to ED pathology. In a meta-analytic review of risk factors for ED pathology, Stice (2002) suggested that according to social learning theory, overweight may lead to increased pressure to be thin, which may be brought on by negative weight comments (e.g., teasing) or exposure to models of ED pathology (e.g., parents/peers/media). In turn, 
perceived pressure to be thin in combination with personality characteristics (e.g., perfectionism) may lead to body dissatisfaction, negative affect, and a cycle of dieting and binge eating (Stice, 2002). While these variables, including thin-ideal internalization, experience of teasing, exposure to models of ED pathology, negative affect, and perfectionism have all been identified as prospective risk factors for ED pathology in community samples (for review, see Stice, 2002), how these variables interact to predict ED pathology specifically among overweight youth has not been examined. A risk model of ED pathology among overweight youth based on social learning theory and previous meta-analytic review (Stice, 2002) may be useful in identifying those in this population who are most vulnerable to the cross-sectional and longitudinal risks associated with ED pathology and overweight.

The present investigation was designed (1) to replicate and build upon the findings from previous studies by comprehensively describing ED pathology and relevant mental health correlates in overweight treatmentseeking youth in order to shed light on the prevalence and clinical significance of ED pathology herein, and (2) to assess a cross-sectional "risk" model of ED pathology in these youth to determine whether constructs emerge that may place youth at increased risk for ED pathology. We hypothesized that a substantial minority of the sample would exhibit ED pathology, which, in turn, would be associated with increased general psychopathology marking its clinical significance. Further, we hypothesized that cross-sectional "risk" modeling would reveal increased thin-ideal internalization, experience of teasing, exposure to models of ED pathology, negative affect, and perfectionism to be associated with increased ED pathology in treatmentseeking overweight youth.

\section{Method}

\section{Participants}

One hundred and twenty-two youth (8-18 years), and one or both parents, were recruited from a population of new patients seeking treatment for overweight through the Optimal Weight for Life (OWL) clinic at the Children's Hospital Boston. To be eligible for participation, children needed to be overweight or at risk for overweight (Ogden et al., 2002). Exclusion criteria were: obesity-related disorders associated with mental retardation; psychotic disorders; and developmental disorders associated with cognitive impairment. During an 18-month period, 450 families were informed about the study by mail. A small minority $(5 \% ; n=22)$ responded to the mailing indicating they wanted no further information about the study. Attempts were made to contact the remaining 428 families by telephone. Of the 302 families reached by telephone, 150 expressed interest and were screened for study inclusion. Thirteen were excluded (12 due to severe cognitive impairment, 1 due to psychosis), and 15 were unable to be scheduled. In total, $122(40 \%)$ of youth contacted by phone met entry criteria and completed the study. There were no significant differences in any demographics or descriptives (e.g., BMI) between children who participated in the study and those who did not (Rhodes and Ludwig, unpublished data).

Child and adolescent participants received a \$25 gift certificate for their participation and parents received $\$ 25$ as compensation for their time.

\section{Procedure}

This study was approved by the Institutional Review Boards at the Children's Hospital Boston and Boston University. All data were collected at baseline, prior to the initiation of treatment. Each child/adolescent gave written assent, and a parent/guardian gave written consent for protocol participation.

\section{Measures}

\section{Diagnostic interviews}

The Eating Disorder Examination version 12.0D/C.2 (Fairburn \& Cooper, 1993) adapted for children (ChEDE; Bryant-Waugh, Cooper, Taylor, \& Lask, 1996) is an interview designed to assess eatingrelated behaviors and cognitions and diagnose specific DSM-IV-TR EDs (APA, 2000). The ChEDE yields 
four-dimensional scales: dietary restraint, eating concern, shape concern, and weight concern and identifies three types of eating episodes: objective overeating accompanied by loss of control (objective binge episode; $\mathrm{OBE}$ ), subjective overeating accompanied by loss of control (subjective binge episode; SBE), and objective overeating without the experience of loss of control (objective overeating; OO). The content of the ChEDE questions comprising the four scales and identifying the eating episodes is identical to that on the adult EDE; the difference between the measures is that the script of the ChEDE has been edited to be more comprehendible to children and adolescents. The ChEDE queries about OBEs for the past 3 months; thus, children who appeared to be binge eating at a rate that may meet diagnostic criteria for BED were queried about the 3 months prior (e.g., 6 months) necessary to make a BED diagnosis. The remaining DSM-IV-TR BED (APA, 2000) criteria were assessed using the BED module from the adult version of the EDE.

Complete description of the training and administration procedure has been described previously (Tanofsky-Kraff et al., 2004). The EDE has shown excellent reliability and validity (Cooper, Cooper, \& Fairburn, 1989; Fairburn \& Cooper, 1993), and studies indicate that the child interview also demonstrates good reliability and validity (Bryant-Waugh et al., 1996; Tanofsky-Kraff et al., 2004; Watkins, Frampton, Lask, \& Bryant-Waugh, 2005).

Children and parents participated in the affective and anxiety disorders modules of the Kiddie Schedule for Affective Disorders and Schizophrenia-present and lifetime version (KSADS-PL; Kaufman et al., 2000) to assess mood and anxiety disorders and data were combined according to Kaufman's recommendations. ${ }^{1}$ The KSADS-PL has demonstrated good psychometric properties including high interrater agreement in diagnoses and test-retest reliability for affective and anxiety disorder diagnoses (Kaufman et al., 1997).

\section{Self-report questionnaires}

The Children's Depression Inventory (CDI; Kovacs, 1992) was administered to assess depressed mood/ negative affect; this measure has strong psychometric properties (e.g., Curry \& Craighead, 1993). The Multidimensional Anxiety Scale for Children (MASC; March, 1998) was used to assess anxiety and has good reliability and concurrent validity with clinical interviews of anxiety disorders (Wood, Piacentini, Bergman, McCracken, \& Barrios, 2002). Children completed the Emotional Eating scale of the Dutch Eating Behavior Questionnaire (DEBQ; Wardle, 1987), which has been used with youth in previous studies (e.g., Braet, Tanghe, Decaluwe, Moens, \& Rosseel, 2004; Moens \& Braet, 2007). The Perception of Teasing Scale-Revised (Thompson, Cattarin, Fowler, \& Fisher, 1995), which has shown good reliability and validity in the assessment of appearance-related teasing in youth (Thompson et al., 1995). The Sociocultural Attitudes Towards Appearance Questionnaire (SATAQ; Heinberg, Thompson, \& Stormer, 1995) was used to assess thin-ideal internalization via recognition and acceptance or internalization of societal standards of appearance and has shown good reliability and validity with children and adolescents (Smolak, Levine, \& Thompson, 2001). The Bulimic Modeling Scale (Stice, 1998) was used to assess perceived family, peer, and media modeling of abnormal eating behaviors including dieting, preoccupation with body shape/weight, unhealthy weight-loss behaviors, and binge eating; this measure has shown good psychometric properties in preliminary studies (Stice, 1998). The 6-item Perfectionism scale of the Eating Disorder Inventory-2 (Garner, 1991) was used to assess perfectionism and has been used with youth (Garner, 1991).

\section{Parent-report questionnaire}

Parents completed the Child Behavior Checklist (CBCL; Achenbach \& Rescorla, 2001) as a measure of child general psychopathology, indexed along scales of Competence, Anxious/Depressed, Social Problems, Internalizing, Externalizing, Total Problems, and diagnostic scales. The CBCL has demonstrated very good psychometric properties (e.g., McConaughy, 1993). Further, the internalizing scale has been found to be increased in association with mood and anxiety disorders and the externalizing scale has been found to be related to the diagnosis of disruptive behavior problems (Edelbrock \& Costello, 1988).

\footnotetext{
${ }^{1}$ One hundred and nineteen child-parent dyads completed the KSADS-PL assessment.
} 


\section{Physical assessment}

Participants were weighed on a calibrated non-digital scale (Detecto, Webb City, MO) in light indoor clothing and height was obtained to the nearest $1 \mathrm{~mm}$ using a calibrated stadiometer. Pubertal stage was assessed (Marshall \& Tanner, 1969, 1970) by an endocrinologist or nurse practitioner during a physical examination.

\section{Statistical analyses}

Between-group comparisons were performed using one-way analysis of variance (ANOVA) for dimensional outcomes, and $\chi^{2}$ analyses for categorical outcomes. Pearson's correlations were used to assess relationships between dimensional variables. To determine relevant covariates, age, gender, ethnicity, BMI $z$-score, and pubertal stage were entered into each full model; non-significant covariates were then removed. There were no significant effects of these covariates on eating behavior group, ChEDE scores, mood or anxiety disorders, or general psychopathology indexed by the CBCL. Gender was used as a covariate in the emotional eating analyses, as emotional eating was found to be greater among girls than boys, $F(1,106)=6.35, p=0.01$. BMI $z$-score was used as a covariate in gender analyses, as boys were heavier than girls, $F(1,121)=7.77, p=0.006$.

Structural equation modeling (SEM) techniques were used to test the cross-sectional "risk" model predicting overall ED pathology (a latent variable comprising binge eating, shape concern, and weight concern). The data were examined for normality by assessing skewness and kurtosis; because the data were multivariate normal, the maximum likelihood (ML) estimator was used. The fit of the data to the model was evaluated using multiple indices to provide a conservative method of evaluating fit and because each index provides different information about the degree of fit (e.g., Jaccard \& Wan, 1996). Hu and Bentler (1999) criteria were used, which recommend that goodness-of-fit is consistent with a non-significant $\chi^{2}$ value, a root mean square error of approximation (RMSEA) close to 0.06 or below, a standardized root mean square residual $(\mathrm{SRMR}) \leqslant 0.08$, and a comparative fit index $(\mathrm{CFI}) \geqslant 0.95$. Additionally, model acceptability was evaluated by examining individual points of strain and considering the strength of the parameter estimates. All data analyses were conducted using the Mplus statistical programming package version 3.12 (Muthén \& Muthén, 2005).

\section{Results}

The 68 females and 54 males ranged in age from 8 to 18 years $(M=11.49, S D=2.30$ years $)$; the majority of the youth were preadolescents $(n=81 ; 66.39 \%))^{2}$ The majority was Caucasian $(61.48 \% ; n=75), 25.41 \%$ $(n=31)$ were African-American, $10.66 \%(n=13)$ were Hispanic, and $2.46 \%(n=3)$ were Asian. The median Tanner stage in the sample was 3.0, with a range from 1.0 to 5.0. Participants' BMI ranged from 20.28 to 63.93 $(M=33.80, S D=7.13) \mathrm{kg} / \mathrm{m}^{2}$; mean BMI $z$-score was $2.39(S D=0.33$; range $1.47,3.30)$; and mean BMI percentile was $98.81(S D=1.25$; range $92.95,99.95)$. With the exception of BMI $z$-score, there were no significant differences between females and males with regard to any demographics.

\section{Eating disorder pathology}

Based on their ChEDE interviews, 10 participants (8.2\%) met criteria for an ED (BED/EDNOS group): seven $(6.6 \%)$ met DSM-IV-TR research diagnostic criteria for BED, and three had another form of EDNOS. Of the three with an EDNOS: (1) the first child reported OBEs 2-3 times per week during the past 6 months that were characterized by eating until uncomfortably full, eating in the absence of hunger, and the experience of shame and guilt following bingeing. Although s/he reported most of the BED criteria, s/he denied "marked" distress about the binge eating, thus earning an EDNOS diagnosis; (2) the second child reported SBEs (3-5 times per week) occurring primarily during the night and occasional $(<1$ times per week) OBEs during the day (both types of binge episodes occurring regularly during the past 6 months), and described

\footnotetext{
${ }^{2}$ Note that between-group analyses and correlations were run separately for the pre-adolescent ( $8-12$ years) and adolescent (13-18 years) samples and found to be the same. SEM analyses were not run separately due to power constraints.
} 
Table 1

ChEDE and emotional eating scores by binge eating status among overweight treatment-seeking youth

\begin{tabular}{|c|c|c|c|c|c|c|}
\hline & $\begin{array}{l}\text { BED/EDNOS } \\
(n=10) \\
\text { Mean }(S D)\end{array}$ & $\begin{array}{l}\text { OBEs } \\
(n=16) \\
\text { Mean }(S D)\end{array}$ & $\begin{array}{l}\text { SBEs } \\
(n=19) \\
\text { Mean }(S D)\end{array}$ & $\begin{array}{l}\text { NEs } \\
(n=77) \\
\text { Mean }(S D)\end{array}$ & $\begin{array}{l}\text { Total sample } \\
\text { Mean (SD) }\end{array}$ & $\begin{array}{l}\text { Test statistic } \\
F(d f), p\end{array}$ \\
\hline Dietary restraint $\mathrm{t}^{\mathrm{a}}$ & $1.28(0.84)$ & $1.26(0.69)$ & $1.45(0.96)$ & $1.26(0.94)$ & $1.28(0.90)$ & $0.41(3,118), 0.75$ \\
\hline Eating concern & $1.80(1.08)^{\mathrm{b}}$ & $1.36(0.83)^{\mathrm{b}, \mathrm{c}}$ & $0.89(0.85)^{\mathrm{c}}$ & $0.32(0.48)^{\mathrm{d}}$ & $0.67(0.82)$ & $23.29(3,118),<0.001$ \\
\hline Shape concern & $3.49(1.24)^{\mathrm{b}}$ & $3.30(1.33)^{\mathrm{b}}$ & $1.97(1.26)^{\mathrm{c}}$ & $1.57(1.14)^{\mathrm{c}}$ & $2.02(1.38)$ & $14.92(3,118),<0.001$ \\
\hline Weight concern & $3.34(1.05)^{\mathrm{b}}$ & $3.18(0.93)^{\mathrm{b}}$ & $2.23(1.13)^{\mathrm{c}}$ & $1.72(1.05)^{\mathrm{c}}$ & $2.13(1.20)$ & $13.55(3,118),<0.001$ \\
\hline Overall ED pathology (ChEDE total) & $2.43(0.74)^{\mathrm{b}}$ & $2.28(0.72)^{\mathrm{b}}$ & $1.64(0.79)^{\mathrm{c}}$ & $1.22(0.59)^{\mathrm{c}}$ & $1.52(0.79)$ & $19.25(3,118),<0.001$ \\
\hline Emotional eating & $2.73(1.27)^{\mathrm{b}}$ & $2.29(.95)^{\mathrm{b}, \mathrm{c}}$ & $1.60(0.58)^{\mathrm{c}}$ & $1.59(0.66)^{\mathrm{c}, \mathrm{d}}$ & $1.78(0.83)$ & $8.56(3,104), 0.001$ \\
\hline
\end{tabular}

${ }^{\text {a }}$ Range for ChEDE scales is 0-6; range for Emotional Eating scale is 1-5.

${ }^{\mathrm{b}-\mathrm{d}}$ Indicate results from posthoc Tukey tests $(p<0.05)$

marked distress and sleep disruption secondary to binge eating; and (3) the third child endorsed recurrent SBEs (14 times per week during the past 6 months) and marked distress about the binge eating. Children with BED or another form of EDNOS were combined in this group. ${ }^{3}$ Note that none of the youth in the BED/ EDNOS group engaged in compensatory behaviors.

A number of children endorsed OBEs or SBEs in the absence of a BED or other EDNOS diagnosis. As such, all participants were categorized into four groups: ED group (BED/EDNOS), OBE group $(n=16$; $13.11 \%$; range $1-2$ episodes per month), SBEs ( $n=19 ; 15.57 \%$; range $1-3$ episodes per month), and those children who had engaged in no loss of control episodes (NE) $(n=77 ; 63.11 \%){ }^{4}$ Participants engaging in more than one type of eating episode were categorized according to the most pathological eating behavior described (i.e., BED/EDNOS, followed by OBE, SBE, and NE).

\section{Associated eating disorder pathology}

Significant main effects of eating behavior group were revealed on ChEDE eating concern, shape concern and weight concern, and on DEBQ emotional eating after controlling for gender (see Table 1). Post hoc Tukey tests indicated no significant differences between the BED/EDNOS and OBEs groups. However, the BED/ EDNOS group demonstrated significantly increased ED pathology (excepting dietary restraint) when compared with the SBEs and NEs groups. The OBEs group had increased shape concern, weight concern, and ChEDE total scores compared with the SBEs and NEs groups. The SBEs had increased eating concern only when compared with the NEs group.

\section{General psychopathology}

On the basis of the KSADS-P/L interview, 48 (40.33\%) youth met criteria for a current mood or anxiety disorder. Twenty-eight $(23.53 \%)$ youth met criteria for a current mood disorder: $15(12.61 \%)$ met criteria for major depression, $12(10.08 \%)$ met criteria for a depressive disorder NOS, and one person $(0.84 \%)$ met criteria for bipolar I disorder. Thirty-three $(27.73 \%)$ youth met criteria for a current anxiety disorder: $9(7.56 \%)$ had generalized anxiety disorder, $8(6.72 \%)$ had social phobia, $8(6.72 \%)$ had a specific phobia, $5(4.20 \%)$ had an

\footnotetext{
${ }^{3}$ Note that the analyses were also run comparing the BED $(n=7)$ group to the three other eating behaviors groups (those endorsing OBEs, SBEs, or NEs) with the other EDNOS youth $(n=7)$ re-grouped according to their largest binge eating episode (i.e., the first and second EDNOS case were categorized in the OBEs group, and the third EDNOS case was categorized in the SBEs group). When the analyses were run utilizing these groups, the pattern of findings was the same, although some between-group differences became smaller as the OBEs and SBEs groups became more heterogeneous with the addition of the EDNOS youth. Thus, children with any type of EDNOS are included in the first group [BED/EDNOS] throughout the Results.

${ }^{4}$ Given the aim of this study was to examine binge eating (loss of control eating) and its clinical relevance, the OOs and NEs groups were combined for the purposes of these analyses into the NEs group. However, all analyses were also run with five groups, in which the NE group was separated into OO without experiencing a loss of control (OOs) or NEs. No significant differences were revealed between the OOs and NEs groups on any variables of interest.
} 
anxiety disorder not otherwise specified, $4(3.36 \%)$ had separation anxiety disorder, and $3(2.52 \%)$ had obsessive compulsive disorder.

\section{Relation of EDs, ED pathology, and mood and anxiety disorders and general psychopathology}

Significant main effects of eating behavior group emerged on depressive (CDI) symptoms, $F(3,118)=6.78$, $p<0.001$, and anxious (MASC) symptoms, $F(3,118)=4.61, p=0.004$, and $\chi^{2}$ analyses indicated effects on current mood disorders that approached statistical significance, $\chi^{2}(3, N=119)=7.59, p=0.06$. Post hoc Tukey tests revealed both the BED/EDNOS and OBEs groups had significantly increased depressive and anxious symptoms when compared to the SBEs and NEs groups. There were no main effects of eating behavior group on CBCL scores or anxiety disorders.

Pearson's correlations demonstrated positive relationships between dimensional ED pathology and selfreported depressive (CDI) and anxiety (MASC) symptoms. Additionally, overall general psychopathology (CBCL Total) was positively associated with shape concern, and CBCL externalizing score was positively associated with shape and weight concern and emotional eating and negatively associated with dietary restraint (Table 2).

\section{Cross-sectional model of putative risk variables}

There were no significant differences between males and females on any of the risk or outcome variables. Further, ANOVAs and Pearson's correlations indicated no significant association between these risk variables and ethnicity, age, BMI $z$-score, or Tanner stage.

Binge eating and shape/weight concerns were significantly related to one another. Intercorrelations among the ED variables and the five risk variables are presented in Table 3.

Table 2

Correlations between eating disorder pathology and general psychopathology

\begin{tabular}{|c|c|c|c|c|c|}
\hline & $\begin{array}{l}C D I \\
r(p)\end{array}$ & $\begin{array}{l}\text { MASC } \\
r(p)\end{array}$ & $\begin{array}{l}\text { CBCL total } \\
r(p)\end{array}$ & $\begin{array}{l}\text { CBCL Int. } \\
r(p)\end{array}$ & $\begin{array}{l}\text { CBCL Ext. } \\
r(p)\end{array}$ \\
\hline Dietary restraint & $0.09(0.34)$ & $0.07(0.47)$ & $-0.18(0.06)$ & $-0.17(0.07)$ & $-0.19(0.04)$ \\
\hline Eating concern & $0.35(<0.001)$ & $0.45(<0.001)$ & $0.03(0.75)$ & $-0.06(0.54)$ & $0.11(0.24)$ \\
\hline Shape concern & $0.56(<0.001)$ & $0.59(<0.001)$ & $0.21(0.02)$ & $0.15(0.11)$ & $0.23(0.01)$ \\
\hline Weight concern & $0.44(<0.001)$ & $0.50(<0.001)$ & $0.17(0.07)$ & $0.12(0.21)$ & $0.22(0.02)$ \\
\hline Overall ED pathology (ChEDE total) & $0.48(<0.001)$ & $0.59(<0.001)$ & $0.12(0.22)$ & $0.05(0.62)$ & $0.16(0.09)$ \\
\hline Emotional eating & $0.52(<0.001)$ & $0.22(0.03)$ & $0.19(0.06)$ & $0.07(0.48)$ & $0.20(0.04)$ \\
\hline
\end{tabular}

CDI, Child Depression Inventory; MASC, Multidimensional Anxiety Scale for Children; CBCL, Child Behavior Checklist (Total, Internalizing, and Externalizing subscales).

Table 3

Pearson's correlations $(r[p])$ among variables included in the cross-sectional risk model

(1)

(1) Binge eating

(2) Shape concern

(3) Weight concern

(4) Teasing

(5) Perfectionism

(6) Modeling

(7) Negative affect

(8) Thin-ideal internalization
(2)

$$
\begin{array}{cc}
0.51(<0.001) & \\
0.50(<0.001) & 0.78(<0.001) \\
0.31(0.001) & 0.44(<0.001) \\
-0.12(0.19) & -0.16(0.08) \\
0.21(0.05) & 0.23(0.03) \\
0.36(<0.001) & 0.56(<0.001) \\
0.31(0.001) & 0.52(<0.001)
\end{array}
$$

(3)

(4)

$$
\begin{aligned}
& 0.35(<0.001) \\
& -0.17(0.07) \\
& 0.20(0.06) \\
& 0.44(<0.001) \\
& 0.39(<0.001)
\end{aligned}
$$$$
-0.17(0.07) \quad-0.34(<0.001)
$$$$
0.20(0.06) \quad 0.22(0.03) \quad-0.19(0.08)
$$$$
0.44(<0.001) \quad 0.47(<0.001) \quad-0.29(0.001) \quad 0.04(0.69)
$$

$0.23(0.01)$
(6)

(7) 


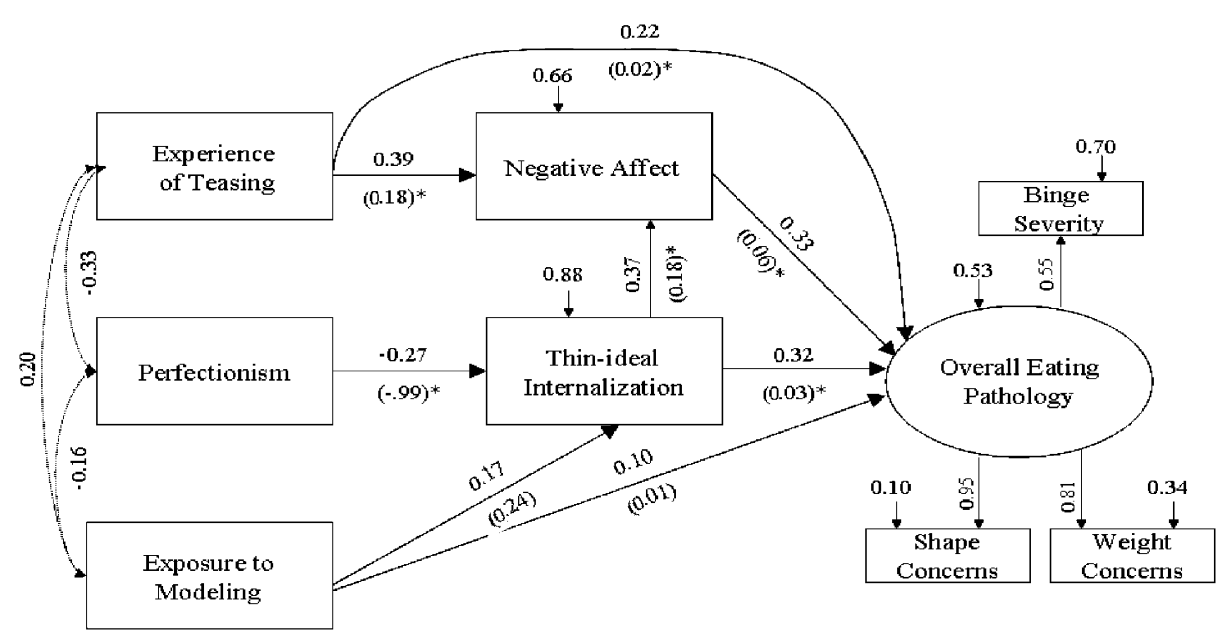

Fig. 1. Cross-sectional risk model for the prediction of overall eating disorder pathology among overweight treatment-seeking youth. Note: Completely standardized paths are listed, unstandardized paths are in parantheses $* p<0.05$.

\section{Structural equation model: predicting ED pathology}

The model fit the data well, $\chi^{2}(14, N=122)=13.81, p=0.46, \quad(R M S E A=0.000, \quad C F I=1.00$, $S R M R=0.039)$ and accounted for $47.60 \%$ of the variance in overall ED pathology. The model complete with standardized and unstandardized beta coefficients is presented in Fig. 1. Local points of strain including modification indices (MIs) and standardized residuals were also examined and found to be acceptable (e.g., MIs < 3.84; $\mid$ standardized residuals $\mid<1.96$ ), indicating that the fit of the model would not be improved by adding direct paths. Notably, the model included one latent variable (overall ED pathology) comprising binge eating (factor loading, $\lambda=0.55$ ), shape concern (factor loading, $\lambda=0.95$ ), and weight concern (factor loading, $\lambda=0.81)$.

\section{Direct paths to overall ED pathology}

Negative affect (standardized $\beta=0.33$; unstandardized $\beta=0.06, t=3.28$ ), thin-ideal internalization (standardized $\beta=0.32$; unstandardized $\beta=0.03, t=3.33$ ), and experience of teasing (standardized $\gamma=0.22$; unstandardized $\gamma=0.02, t=2.41$ ) each had significant direct effects on overall ED pathology. Exposure to modeling (standardized $\gamma=0.10$; unstandardized $\gamma=0.01, t=1.15$ ) had no significant direct effect on overall ED pathology.

\section{Indirect paths to overall ED pathology}

Experience of teasing had a significant indirect effect on overall ED pathology that was mediated by negative affect (standardized $\gamma=0.13$; unstandardized $\gamma=0.01, t=2.76$ ). Similarly, thin-ideal internalization had a significant indirect effect on overall ED pathology that was mediated by negative affect (standardized $\beta=0.12$; unstandardized $\beta=0.01, t=2.73$ ). Exposure to modeling had no significant indirect effects on overall ED pathology (standardized $\gamma=0.08$; unstandardized $\gamma=0.01, t=1.68$ ).

Perfectionism demonstrated significant negative indirect effects on overall ED pathology indicating that increased perfectionism was indirectly associated with a decrease in overall ED pathology. The significant indirect effects of perfectionism on overall ED pathology were mediated by thin-ideal internalization and negative affect (standardized $\gamma=-0.12$; unstandardized $\gamma=-0.04, t=2.51$ ).

\section{Discussion}

In this investigation, we found that a significant minority of children and adolescents presenting for the treatment of overweight exhibited ED pathology including BED, other types of EDNOS, and subthreshold 
binge eating, which were associated with increased shape/weight/eating concerns, and emotional eating. Consistent with the literature on overweight treatment-seeking youth, ED pathology was generally unrelated to demographic variables. Additionally, a minority of the sample met criteria for a mood or anxiety disorder. ED pathology - BED, another form of EDNOS, subthreshold objective binge eating, and eating/shape/weight concerns - was associated with increased depressive, anxious, and externalizing symptomatology. Applying a cross-sectional "risk" model using variables previously identified through community-based studies, we found that ED pathology in overweight youth was predicted by increased negative affect, experience of teasing, thinideal internalization, and exposure to models of ED pathology, and decreased perfectionism.

Our results bolster those of a growing literature that has found substantial ED pathology among treatmentseeking overweight youth. While only a small minority of the sample met criteria for a BED or another form of EDNOS, approximately one-third endorsed loss of control over eating during the last 3 months, which is comparable to previous studies of treatment-seeking overweight youth (Berkowitz et al., 1993; Britz et al., 2000; Decaluwe \& Braet, 2003, 2004; Decaluwe et al., 2003; Goosens et al., in press; Isnard et al., 2003; Levine et al., 2006; Severi et al., 1993). Furthermore, the suggestion that children who endorse any objective binge eating, independent of episode frequency, exhibit increased eating, shape, and weight concerns, is consistent with the existing literature (Berkowitz et al., 1993; Decaluwe \& Braet, 2003, 2004; Decaluwe et al., 2003; Tanofsky-Kraff et al., 2004; Tanofsky-Kraff, Faden, Yanovski, Wilfley, \& Yanovski, 2005). We found that the size of the binge episode was important and related to other types of ED pathology — which is in contrast to the findings from two studies of non-treatment-seeking overweight youth that indicate any loss of control eating is significant (Morgan et al., 2002; Tanofsky-Kraff et al., 2004). In this study, youth with BED, another form of EDNOS, or subthreshold objective binge eating reported significantly increased associated ED pathology compared to those endorsing SBEs or no loss of control eating; there were minimal differences between those endorsing subjective binge eating and those reporting no loss of control eating. In fact, eating, shape, and weight concern in youth with BED, another form of EDNOS, or any OBEs were comparable to those of adults with BED (e.g., Wilfley, Schwartz, Spurrell, \& Fairburn, 1997; Wilfley, Schwartz, Spurrell, \& Fairburn, 2000), and higher than those of healthy non-eating disordered adults (Cooper et al., 1989). It may be that among overweight treatment-seeking youth who are focused upon weight loss, the criterion of ingesting a "large amount of food" accompanied by loss of control, is necessary for the emergence of associated distress and increased eating/shape/weight concerns. Consistent with prior research, the relationship between objective binge eating and disordered eating attitudes, and emotional eating, suggests that objective binge eating is clinically significant even when present at a sub-diagnostic threshold frequency.

Depressive and anxious symptoms were common in these youth, which is also consistent with the limited existing research in this area (e.g., Britz et al., 2000; Erermis et al., 2004; Erickson, Robinson, Haydel, \& Killen, 2000), and approximately $40 \%$ of participants presented with a current mood or anxiety disorder. Also supporting prior research in treatment-seeking overweight children and adolescents (e.g., Berkowitz et al., 1993; Goosens et al., in press; Isnard et al., 2003), depressive and anxious symptoms and current mood disorders were increased in those with either BED, another form of EDNOS, or subthreshold objective binge eating compared to those endorsing only subjective binge eating or no loss of control eating.

In our investigation of the applicability of the cross-sectional prediction model of ED pathology, we found that overall ED pathology was predicted by increased negative affect, thin-ideal internalization, and experience of teasing. Interestingly, overall ED pathology was also predicted by the indirect effects of thin-internalization and experience of teasing, which were mediated by negative affect. The findings in this study are generally consistent with the meta-analytic findings of Stice (2002) describing community samples. To our knowledge, the mediated relationships examined herein have not been studied in community samples.

A novel and unpredicted finding emerged in the application of the model: perfectionism had a negative indirect effect on overall ED pathology mediated by thin-ideal internalization and negative affect. Surprisingly, children endorsing responses consistent with increased perfectionism were less likely to agree with statements regarding beliefs about the importance of being thin, less likely to have negative affect, and in turn, less likely to endorse ED pathology. Although only a limited number of studies have demonstrated that perfectionism is a risk factor for ED pathology (Stice, 2002: mean $r$ based on five studies $=0.06, p<0.025$ ), there is a large body of cross-sectional research that demonstrates the positive association between 
perfectionism and ED pathology, particularly with anorexic symptoms, in healthy weight samples (Shafran, Cooper, \& Fairburn, 2002). At the same time, there is very limited research on the relation between perfectionism and ED pathology in children, and to our knowledge, no published studies exist examining these relationships in overweight youth. Perfectionism may operate differently in children compared to adults, and furthermore, in children who are overweight compared to healthy weight or low weight children. The findings from the present investigation suggest that perfectionism does have relevance to ED pathology - specifically binge eating, shape concern, and weight concern - in overweight youth but that it may represent a protective factor, rather than a risk variable.

It is also possible that the brief (6-item) measure of perfectionism employed did not adequately assess the construct of interest. Notably, the 6-item measure included three items that assess personal standards, and three items that assess parental/familial standards. Instead of true perfectionism, this brief selection of items may have measured constructs similar to self-efficacy or family cohesion, on which high scores may reflect healthy self-esteem and positive familial relationships in this sample, which in turn may be protective against psychopathology (including ED pathology). Further exploration of perfectionism in an overweight child and adolescent sample in relation to ED pathology, general psychopathology, and family functioning is warranted.

The cross-sectional model provided a preliminary examination of how "risk" variables operate together to predict ED pathology in overweight youth, suggesting the relevance of negative affect, teasing, and thin-ideal internalization, and perfectionism to ED pathology in overweight youth, and of exposure to ED models, particularly to binge eating. Prospective, longitudinal studies of overweight youth are needed as a next step to determine whether these cross-sectional "risk" variables indeed represent risk factors for the development of ED pathology among overweight youth, rather than correlates or even effects. Further, longitudinal research could elucidate whether there may be additional specific risk factors that predict the progression from ED pathology to full-syndrome EDs in these youth.

Limitations of the present investigation warrant acknowledgement. Participants were treatment-seeking, thus findings may not be generalizable to community samples. Further, only $40 \%$ of new clinic patients reached by phone completed the study thus it is possible that even within the treatment-seeking population at OWL, participating families may differ from families who opted not (or were ineligible) to participate in the research study. Notably, examination of study completers with clinic data during the recruitment period indicated no differences in demographic or descriptive variables (e.g., BMI $z$-score, age, gender; Rhodes and Ludwig, unpublished data). Thus, it is unlikely that there was a response bias within the clinic sample that impacted study findings, although the replication of these study findings in other clinical overweight samples is needed. Additional limitations include the relatively small sample size, which precluded examination of ED pathology within any specific developmental period, although again, it is noteworthy that age and gender were not generally associated with ED pathology. Finally, the cross-sectional nature of this study rendered the "risk" model preliminary. While this design allowed for comprehensive description of these youth and examination of associated "risk" variables via structural equation modeling, it did not allow for definitive investigation of risk factors or the impact of these variables on treatment course or outcome. In addition, the direct and indirect effects identified in the model were modest and warrant replication.

In conclusion, the findings from this study suggest that routine assessment of the mental health of overweight treatment-seeking youth is justified, as binge eating and associated ED pathology do not seem to simply be a byproduct of overweight status. Moreover, findings from our "risk" model suggest key variables that relate to ED pathology in this population which, following prospective replication, may inform the development of effective interventions for pediatric overweight and prevention of EDs.

\section{Acknowledgments}

This research was supported by 5F31MH071019 (NIMH) and the Charles H. Hood Foundation, Boston, MA. The authors wish to acknowledge David H. Barlow, Ph.D., and Martha C. Tompson, Ph.D. for their thoughtful edits and review of an earlier draft of this manuscript, and Allison Lauretti, Ph.D. for her clinical supervision of this study. 


\section{References}

Achenbach, T. M., \& Rescorla, L. A. (2001). Manual for ASEBA school-age forms \& profiles. Burlington, VT: University of Vermont, Research Center for Children, Youth, \& Families.

American Psychiatric Association. (2000). Diagnostic and statistical manual of mental disorders (4th ed.). Text revision (DSM-IV-TR). Washington, DC: APA Press.

Berkowitz, R., Stunkard, A. J., \& Stallings, V. A. (1993). Binge eating disorder in obese adolescent girls. Annals of the New York Academy of Sciences, 699, 200-206.

Botero, D., \& Wolfsdorf, J. L. (2005). Diabetes mellitus in children and adolescents. Archives of Medical Research, 36, 281-290.

Braet, C. (2006). Patient characteristics as predictors of weight loss after an obesity treatment for children. Obesity, 14, $148-155$.

Braet, C., Tanghe, A., Decaluwe, V., Moens, E., \& Rosseel, Y. (2004). Inpatient treatment for children with obesity. Journal of Pediatric Psychology, 29, 519-529.

Britz, B., Siegfried, W., Ziegler, A., Lamertz, C., Herpertz-Dahlmann, B. M., Remschmidt, H., et al. (2000). Rates of psychiatric disorders in a clinical study group of adolescents with extreme obesity and in obese adolescents ascertained via a population based study. International Journal of Obesity, 24, 1707-1714.

Bryant-Waugh, R. J., Cooper, P. J., Taylor, C. L., \& Lask, B. D. (1996). The use of the EDs examination with children: A pilot investigation. International Journal of Eating Disorders, 19, 391-397.

Cooper, Z., Cooper, P. J., \& Fairburn, C. G. (1989). The validity of the Eating Disorder Examination and its subscales. British Journal of Psychiatry, 154, 807-812.

Curry, J. F., \& Craighead, W. E. (1993). Depression. In T. H. Ollendick, \& M. Hersen (Eds.), Handbook of child and adolescent assessment (pp. 251-268). Nedham Heights, MA: Allyn and Bacon.

Decaluwe, V., \& Braet, C. (2003). Prevalence of binge-eating disorder in obese children and adolescents seeking weight-loss treatment. International Journal of Obesity and Related Metabolic Disorders, 27, 404-409.

Decaluwe, V., \& Braet, C. (2004). Assessment of eating disorder psychopathology in obese children and adolescents: Interview versus selfreport questionnaire. Behaviour Research and Therapy, 42, 799-811.

Decaluwe, V., Braet, C., \& Fairburn, C. G. (2003). Binge eating in obese children and adolescents. International Journal of Eating Disorders, 33, 78-84.

Dietz, W. H. (1995). Childhood obesity: Prevalence and effects. In K. D. Brownell, \& C. G. Fairburn (Eds.), Eating disorders and obesity (pp. 438-440). New York: The Guilford Press.

Ebbeling, C. B., Pawlak, D. B., \& Ludwig, D. S. (2002). Childhood obesity: Public-health crisis, common sense cure. Lancet, $360,473-482$.

Edelbrock, C., \& Costello, A. J. (1988). Convergence of statistically derived behavior problem syndromes and child psychiatric diagnoses. Journal of Abnormal Child Psychology, 16, 219-231.

Epstein, L. H., Wisniewski, L., \& Weng, R. (1994). Child and parent psychological problems influence child weight control. Obesity Research, 2, 509-515.

Erermis, S., Cetis, N., Tamar, M., Bukusoglu, N., Akdeniz, F., \& Goksen, D. (2004). Is obesity a risk factor for psychopathology among adolescents. Pediatrics International: Official Journal of the Japan Pediatrics Society, 46, 296-301.

Erickson, S. J., Robinson, T. N., Haydel, F., \& Killen, J. D. (2000). Are overweight children unhappy? Archives of Pediatric Adolescent Medicine, 154, 931-935.

Fairburn, C. G., \& Cooper, Z. (1993). The Eating Disorder Examination (12th ed.). In C. G. Fairburn, \& G. T. Wilson (Eds.), Binge eating: Nature, assessment and treatment (pp. 333-360). New York: Guilford Press.

Garner, D. M. (1991). Eating Disorders Inventory -2: Professional manual. Odessa, FL: Psychological Assessment Resources.

Glasofer, D. R., Tanofksy-Kraff, M., Eddy, K. T., Yanovski, S. Z., Theim, K. R., Mirch, M. C., et al. (2007). Binge eating in overweight treatment-seeking adolescents. Journal of Pediatric Psychology, 32, 95-105.

Goossens, L., Braet, C., \& Decaluwe, V. (2007). Loss of control over eating in obese youngsters. Behaviour Research and Therapy, 45, 1-9.

Heinberg, L. J., Thompson, J. K., \& Stormer, S. (1995). Development and validation of the Sociocultural Attitudes Towards Appearance Questionnaire. International Journal of Eating Disorders, 17, 81-89.

Hu, L., \& Bentler, P. M. (1999). Cutoff criteria for fit indexes in covariance structure analysis: Conventional criteria versus new alternatives. Structural Equation Modeling, 6, 1-55.

Isnard, G., Michel, P., Frelut, M. L., Vila, G., Falissard, B., Naja, W., et al. (2003). Binge eating and psychopathology in severely obese adolescents. International Journal of Eating Disorders, 34, 235-243.

Jaccard, J., \& Wan, C. K. (1996). LISREL approaches to interaction effects in multiple regression. Thousand Oaks, CA: Sage Publications.

Kaufman, J., Birmaher, B., Brent, D., Rao, U., Flynn, C., Moreci, P., et al. (1997). KSADS-PL: Initial reliability and validity. Journal of the American Academy of Child and Adolescent Psychiatry, 36, 980-988.

Kaufman, J., Birmaher, B., Brent, D., Rao, U., Flynn, C., Moreci, P., et al. (2000). Task force for the handbook of psychiatric measures. Washington, DC: APA Press.

Kovacs, M. (1992). Children's Depression Inventory manual. North Tonowanda, NY: Multi-Health Systems, Inc.

Levine, M. D., Ringham, R. M., Kalarchian, M. A., Wisniewski, L., \& Marcus, M. D. (2006). Overeating among seriously overweight children seeking treatment: Results of the Children's Eating Disorders Examination. International Journal of Eating Disorders, 39, 135-140.

March, J. (1998). Multidimensional Anxiety Scale for Children (MASC). Toronto: Multi-Health Systems, Inc. 
Marshall, W. A., \& Tanner, J. M. (1969). Variations in pattern of pubertal changes in girls. Archives of Disorders of Childhood, 44, 291-303.

Marshall, W. A., \& Tanner, J. M. (1970). Variations in the pattern of pubertal changes in boys. Archives of Disorders of Childhood, 45, $13-23$.

McConaughy, S. H. (1993). Evaluating behavioral and emotional disorders with the CBCL, TRF, and YSR cross-informant scales. Journal of Emotional and Behavioral Disorders, 1, 40-52.

Moens, E., \& Braet, C. (2007). Predictors of disinhibited eating in children with and without overweight. Behaviour Research and Therapy, $45,1357-1368$

Morgan, C. M., Yanovski, S. Z., Nguyen, T. T., McDuffie, J., Sebring, N. G., Jorge, M. R., et al. (2002). Loss of control over eating, adiposity, and psychopathology in overweight children. International Journal of Eating Disorders, 31, 430-441.

Must, A., Jacques, P. F., Dallal, G. E., Bajema, C. J., \& Dietz, W. H. (1992). Long-term morbidity and mortality of overweight adolescents. A follow-up of the Harvard Growth Study of 1922 to 1935. New England Journal of Medicine, 327, 1350-1355.

Muthén, B. \& Muthén, L. (2005). Mplus Version 3.12. 〈http://www.statmodel.com/index2.html〉

Ogden, C. L., Carroll, M. D., Curtin, L. R., McDowell, M. A., Tabak, C. J., \& Flegal, K. M. (2006). Prevalence of overweight and obesity in the United States, 1999-2004. Journal of the American Medical Association, 295, 1549-1555.

Ogden, C. L., Kuczmarski, R. J., Flegal, K. M., Mei, Z., Guo, S., Wei, R., et al. (2002). Centers for Disease Control and Prevention 2000 Growth Charts for the United States: Improvements from the 1977 National Center for Health Statistics Version. Pediatrics, 109, 45-60.

Severi, F., Verri, A., \& Livieri, C. (1993). Eating behaviour and psychological profile in childhood obesity. Advances in the Biosciences, 90 , $329-336$.

Shafran, R., Cooper, Z., \& Fairburn, C. G. (2002). Clinical perfectionism: A cognitive-behavioral analysis. Behaviour Research and Therapy, 40, 773-791.

Smolak, L., Levine, M. P., \& Thompson, J. K. (2001). The use of the sociocultural attitudes towards appearance questionnaire with middle school boys and girls. International Journal of Eating Disorders, 29, 216-223.

Spitzer, R. L., Devlin, M., Walsh, B. T., Hasin, D., Wing, R. R., Marcus, M., et al. (1992). Binge-Eating Disorder: A multisite field trial of the diagnostic criteria. International Journal of Eating Disorders, 3, 191-203.

Spitzer, R. L., Yanovski, S., Wadden, T., Wing, R., Marcus, M. D., Stunkard, A., et al. (1993). Binge ED: Its further validation in a multisite study. International Journal of Eating Disorders, 13, 137-153.

Stice, E. (1998). Modeling of eating pathology and social reinforcement of the thin-ideal predict onset of bulimic symptoms. Behaviour Research and Therapy, 36, 931-944.

Stice, E. (2002). Risk and maintenance factors for eating pathology: A meta-analytic review. Psychological Bulletin, 128, 825-848.

Stice, E., Cameron, R. P., Killen, J. D., Hayward, C., \& Taylor, C. B. (1999). Naturalistic weight-reduction efforts prospectively predict growth in relative weight and onset of obesity among adolescent females. Journal of Consulting and Clinical Psychology, 67, 967-974.

Stice, E., Presnell, K., \& Spangler, D. (2002). Risk factors for binge eating onset in adolescent girls: A 2-year prospective investigation. Health Psychology, 21, 131-138.

Tanofsky-Kraff, M. (In press). Binge eating among children and adolescents. In E. Jelalian \& R. Steele (Eds.), Handbook of child and adolescent obesity (Subject to peer-review). Springer Publishers.

Tanofsky-Kraff, M., Cohen, M. L., Yanovski, S. Z., Cox, C., Theim, K. R., Keil, M., et al. (2006). A prospective study of psychological predictors for body fat gain in children at high-risk for adult obesity. Pediatrics, 117, 1203-1209.

Tanofsky-Kraff, M., Faden, D., Yanovski, S. Z., Wilfley, D. E., \& Yanovski, J. A. (2005). The perceived onset of dieting and loss of control eating behaviors in overweight children. International Journal of Eating Disorders, 38, 112-122.

Tanofsky-Kraff, M., Yanovski, S. Z., Wilfley, D. E., Marmarosh, C., Morgan, C. M., \& Yanovski, J. A. (2004). Eating disordered behaviors, body fat, and psychopathology in overweight and normal weight children. Journal of Consulting and Clinical Psychiatry, 72, 53-61.

Thompson, J. K., Cattarin, J., Fowler, B., \& Fisher, E. (1995). The Perception of Teasing Scale (POTS): A revision of the physical appearance related teasing scale (PARTS). Journal of Personality Assessment, 65, 146-157.

Wardle, J. (1987). Eating style: A validation study of the Dutch Eating Behaviour Questionnaire in normal subjects and women with eating disorders. Journal of Psychosomatic Research, 31, 161-169.

Watkins, B., Frampton, I., Lask, B., \& Bryant-Waugh, R. (2005). Reliability and validity of the child version of the Eating Disorder Examination: A preliminary investigation. International Journal of Eating Disorders, 38, 183-197.

Wilfley, D. E., Schwartz, M. B., Spurrell, E. B., \& Fairburn, C. G. (1997). Assessing the specific psychopathology of binge eating disorder patients: Interview of self-report? Behaviour Research and Therapy, 35, 1151-1159.

Wilfley, D. E., Schwartz, M. B., Spurrell, E. B., \& Fairburn, C. G. (2000). Using the Eating Disorder Examination to identify the specific psychopathology of binge eating disorder. International Journal of Eating Disorder, 27, 259-269.

Whitaker, R. C., Wright, J. A., Pepe, M. S., Siedel, K. D., \& Dietz, W. H. (1997). Predicting obesity in young adulthood from childhood and parental obesity. New England Journal of Medicine, 337, 869-873.

Wood, J. J., Piacentini, P. C., Bergman, R. L., McCracken, J., \& Barrios, V. (2002). Concurrent validity of the Anxiety Disorders Interview Schedule for DSM-IV: Parent and child versions. Journal of Clinical Child and Adolescent Psychiatry, 31, 335-342. 